Session 3147

\title{
Problem Solving in Engineering Technology: Creativity, estimation and critical thinking are essential skills
}

\author{
Barry M. Lunt, C. Richard G. Helps \\ Electronics Engineering Technology \\ Brigham Young University
}

The process of design is basically a problem-solving process, and consists of the following steps: 1) develop functional specifications; 2) develop the concept design; 3) generate design alternatives; 4) select and model the best alternatives; and 5) test and verify the design. ${ }^{1}$ Because the process of design is a main focus of most 4-year programs in engineering technology, it is essential that students be taught the skills that will make them proficient in design. Three key skills which are essential are creativity, estimating, and critical thinking.

The ability to think creatively is the skill that allows the designer to step ahead beyond what already exists, and to envision what does not yet exist. It is particularly useful in steps 1, 2, 3, and 5 of the design process outlined above. The ability to estimate allows the designer to look ahead to assess feasibility, to look back to verify assumptions and calculations, and to around to keep one's feet on the ground during the design process. It is very useful at all steps of the design process. And lastly, the ability to think critically allows the designer to move through the design process step by step, while checking the intermediate results for validity and applicability. It is essential in all the preceding design steps.

Students enrolling in engineering technology (ET) quickly acquire a toolbox of ideas, knowledge, and thinking skills. The thinking skills they acquire should be among the sharpest, most versatile, and most oft-used tools in their toolbox. The degree to which students are successful in building and applying these tools is dependent on the degree to which we specifically teach them and apply them in our curriculum. Because the manner in which they integrate all these tools into their ET experience has a significant effect on the success of their career and university experience, we believe there should be a greater focus on these three specific thinking skills.

\section{Creativity}

Technical students, particularly Engineering Technology students, are expected to create a number of devices or systems during their student career, and probably many more after they have graduated. They are also often called on to generate multiple solutions to a single need or problem. In these activities, they can benefit greatly from learning how to think creatively. "In the competitive marketplace, [creativity is] a crucial asset in the bid to win the race to build better machines, decrease product delivery times, and anticipate the needs of future generations." Additionally, "Engineers and technologists bring mathematics and science to bear 
on practical problems, molding natural materials and harnessing technology for human benefit."3

A prominent scholar in the field of creative thinking is Edward de Bono ${ }^{4}$, whose seminal work "Lateral Thinking," published in 1970, is still widely quoted and used. ${ }^{3}$ He argues convincingly that these essential creative thinking skills can be taught. This thinking has since been further solidified: "Creativity is now regarded as a mental ability that may be improved by training.", De Bono proposes that creative thinking can be enhanced by thinking "laterally" rather than in the careful, step-by-step manner in which designers often think. The following diagram taken from Lateral Thinking demonstrates this concept.

$1 \mathrm{a}$

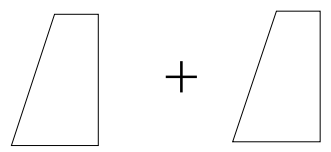

$1 b$

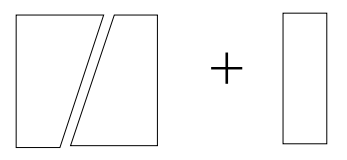

$1 \mathrm{c}$
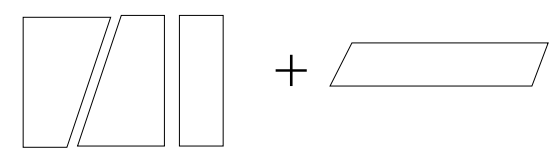

$1 d$

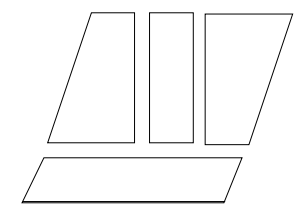

The challenge: take the two shapes shown in Fig. 1a and form a parallelogram. A solution is shown in Fig. 1b. The next challenge: add a third shape and once again form a parallelogram. Once again this is easily solved, as shown in Fig. 1c. The next challenge (add a fourth shape and again form a parallelogram) causes problems. We have followed a sequence of events that cannot be continued. This illustrates the problem of "vertical thinking." We follow a particular line of thinking until we come to a dead end. Yet a simple solution does exist, the solution to which can only be found by breaking up the existing structure and starting anew to get the shape in Fig. 1d. This breaking of the assumed rules is the essence of lateral thinking.

We teach a related thinking style to students when we teach "brainstorming." One of the fundamental rules of brainstorming is that no idea may be criticized, no matter how crazy. All present must be free from any assumed rules in order for the process to work. This relief from conventional rules is essential to inspire ideas that, in the end, are often very practical. We must guard against encouraging students to believe that there is only one right answer to each problem. Suspension of critical faculties is essential to identify new solutions to a problem.

Creativity can be developed with thinking puzzles. A common variant of the above parallelogram exercise is "block puzzles". A number of wooden blocks must be arranged into a square or into many different shapes to resemble (with some imagination) animals, airplanes, or flowers. Alternatively, the blocks must be arranged so that they have some specific relationship to each other. Word puzzles also promote creative thinking. A common puzzle states "A big Indian and a little Indian are walking though the desert hunting for food. The little Indian is the big Indian's son but the big Indian is not the little Indian's father. Who is the big Indian?". Here the imagination must step out of the boundaries of the stated information and the stereotypes deliberately introduced into the problem, to come up with the answer - his mother. This kind of word puzzle makes an excellent in-class exercise to develop creative thinking; other examples may be found in the literature ${ }^{6}$. 
Creativity and the practical realization of great ideas are at the heart of E.T. A brilliant new concept or scientific principle may promise great technological progress but it could take years or even lifetimes to bring to fruition. Thus, Alan Turing's 1936 concept of a thinking machine only appeared in practice (after his death) with the personal computer in the late 1980's - which even now is only a crude approximation of his dream. Students must be encouraged to dream and to think creatively. Techniques such as those of de Bono exist, and must be disseminated so we can properly equip their "tool box."

\section{Estimation}

The field of engineering technology is renowned for generally requiring completion of some calculus for all its majors. Given that essentially all students in engineering technology are competent in math, and that computers and calculators are widely available, what is the value of approximate answers? For one thing, exact calculation and estimation are very different skills, and even take place in a different part of the brain. ${ }^{7}$ Additionally, "computational estimation has long been recognized as a basic mathematical skill," 8 but it "is perhaps the most neglected skill area in the mathematics curriculum" (ibid). Paull found a significant correlation between estimation competency and problem solving ability, and that "the ability to compute rapidly was related to the ability to estimate numerical computation." "And finally, we reference the common experience of all engineers when faced with a problem; the ability to estimate the feasibility of a given proposal is greatly helpful in the process of finding a practical solution.

Every engineering technologist will be faced with the questions "How long will this take"? "How much will it cost"? "Can we do this"? These questions will come from customers, senior management, colleagues, and from the technologist herself. Learning to estimate is a normal part of university education, but it is rarely taught explicitly. Detailed estimates involve a parts list, project charts, manufacturers catalogs, and many hours. A great deal of time, effort, and money can be saved if a faster estimate can be obtained bypassing the normal, logical steps described above. Once again, there are well-documented techniques to help develop the necessary skills. One of the better-known techniques is known as the Fermi Solution. Hans Christian von Baeyer ${ }^{10}$ introduces the idea with this anecdote.

At twenty-nine minutes past five, on a Monday morning in July of 1945, the world's first atom bomb exploded in the desert sixty miles northwest of Alamogordo, New Mexico. Forty seconds later, the blast's shock wave reached the base camp, where a cluster of scientists stood in stunned contemplation of the historic spectacle. The first person to stir was the Italian-American physicist Enrico Fermi, who was on hand to witness the culmination of a project he had helped to initiate.

Before the bomb detonated, Fermi had torn a sheet of notebook paper into small bits. Then, as he felt the first quiver of the shock wave spreading outward through the still air, he released the shreds above his head. They fluttered down and away from the mushroom cloud growing on the horizon, landing about two and a half yards behind him. After a brief mental calculation, Fermi announced 
that the bomb's energy had been equivalent to that produced by ten thousand tons of TNT. Sophisticated instruments were also at the site, and analysis of their readings of the shock wave's velocity and pressure, an exercise that took several weeks to complete, confirmed Fermi's instant estimate.

Fermi problems are distinguished from purely logical problems, such as the block problems cited previously. Logical problems contain all the elements of the solution within themselves. The process of estimation by lists is a logical problem. No solution is obtained until sufficient information has been collected. Fermi problems, on the other hand, are solved with information that is already available. Consider another example of a Fermi problem from von Baeyer. ${ }^{10}$

How many piano tuners are there in Chicago? The whimsical nature of this question, the improbability that anyone knows the answer, and the fact that Fermi posed it to his classes at the University of Chicago have elevated it to the status of legend. There is no standard solution (that's exactly the point), but anyone can make assumptions that quickly lead to an approximate answer. Here is one way: If the population of metropolitan Chicago is three million, an average family consists of four people, and one third of all families own pianos, there are two hundred and fifty thousand pianos in the city. If every piano is tuned once every five years, fifty thousand pianos must be tuned each year. If a tuner can service four pianos a day, two hundred and fifty days a year, for a total of one thousand tunings a year, there must be about fifty piano tuners in the city. The answer is not exact; it could be as low as twenty-five or as high as a hundred. But, as the yellow pages of the telephone directory attest, it is definitely in the ballpark.

Fermi's intent was to show that although, at the outset, even the answer's order of magnitude is unknown, one can proceed on the basis of different assumptions and still arrive at estimates that fall within range of the answer. The reason is that, in any string of calculations, errors tend to cancel one another out. If someone assumes, for an instance, that every sixth, rather than third, family owns a piano, they are just as likely to assume that pianos are tuned twice in five years, instead of once. It is as improbable that all of one's errors will be underestimates (or overestimates) as it is that all the throws in a series of coin tosses will be heads (or tails). The law of probabilities dictates that deviations from the correct assumptions will tend to compensate for one another, so the final results will converge toward the right number. (Ibid, p. 7)

The Fermi approach to estimation can now be summarized, and a list of characteristics of Fermi problems can now be generated:

(1) On first being encountered, they seem to be insolvable. There just doesn't seem to be enough information.

(2) They are solved by breaking them down into smaller problems, recursively if necessary, until solutions are known or can be estimated. The way a problem is broken down depends on the individual. What facts does he have in his "junk box"? Sometimes 
several different decompositions must be attempted. This requires some of the creative skills mentioned earlier.

The final solution is compiled by simple arithmetic from the individual sub-problems.

Errors tend to cancel out. Overestimating in one area is often compensated for by underestimating in another. This is a statistical phenomenon, not a human phenomenon.

It is understood that estimates are not exact, and that they can be erroneous. To overcome concerns about accuracy, two estimates can be done; if the estimates agree and were obtained by different methods they provide evidence of the validity of the estimate

Other important applications of estimation skills exist. One example is in the area of problem solving. A few decades ago, many engineers, raised on the discipline of a slide rule, learned the skill of quickly estimating the order of magnitude of an answer. Later, when they converted (quite willingly!) to calculators, these same engineers saw the value of the skill they were no longer required to use. Calculators can give you every possible answer to the question at hand, and it is up to the user to distinguish a correct answer from an erroneous answer resulting from a sticky button, incorrect sequence, "fat-finger" entry error, or misplaced parenthesis. However, many of today's engineers, raised on calculators, have never learned the skill of estimating. This is evidenced by the outrageous answers they occasionally give to a particular problem, only to explain such answers by stating, "It's what my calculator [computer, spreadsheet, etc.] gave me!"

Another example lies in the area of answer checking. Too often, inexperienced problem solvers will take an answer or group of answers as correct, without checking to see if the answer even makes sense. For example, if an engineer or computer scientist were to encode an algorithm for solving the infamous problem of the traveling salesman (find the shortest route to visit the capitals of all 50 U.S. states), and the first answer were to range in the neighborhood of 3,000 miles, would the answer be believable? Or would the problem solver recognize how absurdly low the answer is?

A third application lies in the area of making modifications. If a given circuit operates at the wrong frequency, how much would a given component have to change to bring it to the desired frequency? Or if you happen to have only a certain value for a needed component, and you put it in parallel with another similar component, what effect would you expect to see? How large do you expect that effect to be? The answers to these questions are quickly found by estimation, which is much faster than exact calculation, and for much testing of prototypes is sufficiently accurate for the work being conducted.

A final, but very important, advantage to learning the skill of estimating is that to estimate well, one must truly understand the entire system. An exact calculation only requires that one choose the correct equation and provide the correct values for all variables: the source of the values does not need to be understood, nor does their relation to the system as a whole. Even the equation does not need to be understood for an exact answer to be found; one need merely "plug and 
chug." A rough estimate often carries more credibility than an answer with many digits of resolution, simply because we understand how we arrived at our estimate, while we may not understand the equation that led us to the high-resolution answer

\section{Critical Thinking}

This tool has been defined as "the ability to analyze information, to determine the truth and validity of statements and information, and to translate that information to fill gaps in personal knowledge." 11,12,13,14 There are several excellent reasons cited in the preceding references for critical thinking being an essential skill; one of these is particularly applicable in the field of engineering technology. Specifically, it has been shown that improved critical thinking is strongly correlated to improvement in problem solving ability. ${ }^{13}$

Table 1, taken from Jegede and Noordink, ${ }^{13}$ outlines several variables associated with critical thinking, and gives the mean rating of the importance of these variables, as determined by a survey they conducted. A mean rating of 4.0 or greater was considered to be important to success. The table which follows gives only those variables which scored 4.0 or higher.

A quick scan of the variables listed in Table 1 is very convincing; it is easy to accept that a student strong in these variables (skills) would also be very skilled at problem solving. Given the importance of developing critical thinking skills for students in the field of engineering technology, how is this to be done? Allen ${ }^{15}$ and Ausubel ${ }^{16}$ argue that it is a basic function of education to teach these skills; hence these skills are taught throughout the post-secondary educational experience. But is it enough to assume that our engineering technology students are becoming adept at these as the proceed through their formal education, or should we be specifically teaching it? And should we concern ourselves with assessment of their critical thinking skills?

We argue that because critical thinking skills are so helpful in a field that stresses problemsolving abilities, some kind of attention should be specifically directed toward this end. The literature strongly supports the concern that the ability to think critically is not widespread, and that post-secondary education has a fundamental responsibility to train students in this. ${ }^{17}$ Perhaps all students should be tested as to their critical thinking skills; such tests do exist ${ }^{18,19}$ and are well accepted. However as valuable as the results of these tests would be, we do not believe that their general application in engineering technology education is warranted.

Another possibility is requiring all engineering technology students to take a class in critical thinking, along with other aspects of the thinking process. There is no doubt that such a class would help. However, the literature is mixed on whether it is better to teach critical thinking skills outside of a specific domain of knowledge, and in fact, "there is good reason to believe...that principles of critical thinking taught without any view to their application to real world problems will not be beneficial." ${ }^{17}$ (emphasis in original)

Accordingly, our recommendation is to give formal lectures with exercises on the topic of critical thinking within the structure of a freshman cornerstone course, and to then require students to use these skills repeatedly throughout their college experience, especially in their 


$\left.\begin{array}{||l|c||}\hline \multicolumn{1}{|c||}{\text { Variables }} & \text { Mean Rating } \\ \hline \hline \text { Revise a previously held view to account for new information } & 4.06 \\ \hline \text { Determine associations between similar ideas, objects and situations } & 4.07 \\ \hline \text { Analyze knowledge within a given domain and context } & 4.17 \\ \hline \text { Be willing to evaluate an argument or proposition posed by an authority } & 4.17 \\ \hline \text { Generate solutions to problems } & 4.23 \\ \hline \text { Identify the most significant variables involved in a problem } & 4.23 \\ \hline \text { Relate what kind of evidence will support a thesis or hypothesis } & 4.23 \\ \hline \text { Produce an argument that is internally consistent } & 4.30 \\ \hline \text { Clearly identify central issues and problems to be investigated or hypothesis } \\ \text { to be tested }\end{array}\right)$

Table 1: Critical thinking variables rated as very important to success.

engineering technology major. The formal lectures help students recognize critical thinking skills, understand their value, and begin to improve them. The skills listed previously in Table 1 make an excellent starting point for developing such a lecture.

\section{Summary}

Design is basically a problem solving process, and is a major focus of most 4-year engineering technology programs. The design process, outlined in the introduction to this paper, is greatly aided at each step by proper thinking skills. Three of the most important thinking skills for the design process are creativity, critical thinking, and estimation.

Creativity allows designers to envision what does not presently exist; critical thinking skills are essential to designers as they evaluate their intermediate results throughout the design process; and estimation is an essential thinking skill which enables designers to ascertain what is reasonable and acceptable. Engineering technology students should be taught these thinking skills explicitly, preferably in a freshman cornerstone type of class. 


\section{References}

1. King, J . Exploring Engineering; Menlo Park, CA: Addison-Wesley (1996).

2. Gibney, K. Awakening creativity. ASEE Prism, American Society for Engineering Education, Washington, D.C., 19-23 (1998), p 20.

3. Sadowski, M. A. \& Connolly, P. E. Creative thinking: The generation of new and occasionally useful ideas. Engineering Design Graphics Journal, 63(1) (Winter 1999).

4. De Bono, E. Lateral Thinking. New York: Harper \& Row (1973).

5. Harrisberger, L. Engineersmanship-: The doing of engineering design, ( ${ }^{\text {nd }}$ Edition). Belmont, CA: Wadsworth Inc. p 52.

6. Connolly, P. E. \& Sadowski, M. A. Creativity development in a freshman level engineering graphics course - an application. Engineering Design Graphics Journal, 63(3) (Fall 1999).

7. Fisher, A. Natural Genius. Popular Science, Jan 2000, 68-72.

8. Reys, R. E., Bestgen, B. J., Rybolt, J. F., \& Wyatt, J. W. Processes used by good computational estimators. Journal for Research in Mathematics Education, May 1982, p. 183-201.

9. Paull, D. R. The ability to estimate in mathematics (Doctoral dissertation, Columbia University, 1971). Dissertation Abstracts International, 1971, 32, 3567A. (University Microfilms No. 71-20,736).

10. Von Baeyer, Hans Christian, The Fermi Solution, New York: Random House (1993).

11. Ennis, R. H. Critical thinking and subject specificity: Clarification and needed research. Educational Researcher, 18(3), 4-10 (1989).

12. Gagne, R. M. Some reflections on thinking skills. Instructional Science, 17, 387-390. (1988).

13. Jegede, O. J.\& Noordink, P. The role of critical thinking skills in undergraduate study as perceived by university teachers across academic disciplines. ED362122 (1993). p 4.

14. McPerk, J. E. Critical Thinking and Education. Oxford: Martin Roberston (1981).

15. Allen, M. The Goals of Universities. Milton Keynes: the Society for Research into Higher Education and the Open University (1988).

16. Ausubel, D. Learning as constructing meaning. In N. Entwistle (Ed.). New Directions in Educational Psychology 1: Learning and Teaching. London: Falmer (1985).

17. Norris, S. P. Synthesis of research on critical thinking. Educational Leadership, May 1985, p 40-45 (emphasis in original).

18. Ennis, R. H. \& Millman, J. Cornell critical thinking tests, levels X and Z. Pacific Grove, CA: Midwest Publications (1985).

19. Watson, G. \& Glaser, E.M. Watson-Glaser critical thinking appraisal, Forms A and B. Cleveland, OH. 1980.

\section{BARRY LUNT}

Barry M. Lunt is an Associate Professor of Electronics Engineering Technology at Brigham Young University in Provo, UT. Dr. Lunt received a B.S. and an M.S. degree in Electronics Engineering Technology from Brigham Young University, and a Ph.D. in Occupational and Adult Education from Utah State University in Logan, UT. He has spent seven years in industry as a design engineer. His present research emphases are the physical design of electronic circuits and systems, and engineering education.

\section{RICHARD HELPS}

C. Richard G. Helps is the Program Chair of the Electronics Engineering Technology program at BYU. He spent ten years in industry as a control systems design engineer. He completed BS and MS degrees at the U of the Witwatersrand, South Africa and a further graduate degree at the University of Utah. His primary interests are in instrumentation and control systems, particularly embedded control systems, combined with artificial intelligence techniques such as neural networks and fuzzy logic. 